\title{
The Patient who cannot afford the bus fare to the clinic
}

In his book Equanimitas, written in 1904, Sir William Osler laments that very few doctors go into public life to help advise and manage the delivery of health care. "As a rule," he says "doctors make bad citizens taking little or no interest in civic, state or national politics". Most of us do not like leaving the comfort zone of clinical medicine and entering the more robust arena of medical politics.

We teach students how to use an asthma inhaler so that the lung functions stay normal and explain the management of diabetes to achieve normal blood glucose levels. We then pack up our bags and go home - job done. There is little space in the curriculum to discuss with students the wider issues about the real world outside the hospital and clinic walls.

What can a health worker do to speak out? There are now various frameworks for helping to set up equity-driven policies and patient advocacy (Voice). There are also systems for enabling health care workers to act as agents for change that are now being included in medical school curricula as well as by the HPCSA (Advocacy for Health). The problem is getting through the firewalls and reinforced concrete ceilings of the Departments of Health and then upwards to the big birds on the upper floor.

I have now devised a module to be included in the curriculum and then a question paper for the final MB examination. It is in my new discipline which is called Strategies for the Management of Health Care Services, and I have seven magnificently subversive questions on the exam paper:

1. You are working in a suburban clinic. You have a patient with asthma who is well controlled with a Budesonide inhaler, which is the only steroid inhaler on code. Your staff nurse informs you that due to supply chain management failure they will not be able to supply Budesonide for the next three months. After you have calmed down from an incandescent rage to a controlled fury, explain your further management of this patient and give suggestions for additional strategic management systems that could be introduced.

2. You raise this supply management problem with your immediate supervisor who informs you that "there is very little that can be done about it" so you write to the Department of Health but receive no reply. Indicate the further actions that you could take in this matter as a South African citizen.

3. It has been reported recently in the press that at Inkosi Albert Luthuli hospital, which is a specialist tertiary hospital, an operation has taken place to separate conjoined twins. The operation took 13 hours and involved 23 specialists and was done at great expense. Several streets away from the hospital are shack dwellings with raw sewerage flowing past the shacks. Malnourished children from this area are dying from gastroenteritis. Discuss the concept of distributive justice as it applies to these two situations.

4. It is said that there are now about 1500 guidelines worldwide for the management of the different diseases and conditions of the $21^{\text {st }}$ century. Common ones are guidelines for the management of hypertension, diabetes and asthma. Statistics SA released figures that show that about 13 million of our people are living in extreme poverty (that is extreme poverty not just poverty). About $20-30 \%$ of our population does not have full access to health care and $10-20 \%$ cannot afford the bus fare to their local clinic. It has been proposed that an addendum is added to clinical guidelines in South Africa to the effect that the guidelines only apply to those who have access to health care. Discuss the reasons for adding or omitting this proposal.

5. It has been suggested that those hospitals/departments/ clinics that are functioning at substandard levels of care display a visible notice outside their facility:

\section{THIS HOSPITAL/DEPARTMENT/CLINIC DOES NOT MEET \\ THE MINIMUM STANDARDS OF MEDICAL CARE. \\ This would be similar to the notice in the car park that states:}

\section{CARS ARE PARKED AT YOUR OWN RISK.}

Discuss the advantages and disadvantages of such notices.

6. The population of South Africa is about 55 million and it is projected to increase to 75 million in the next few decades. This will cause enormous demand on hospitals, clinics and health services. The total budget for health services is approximately 188 billion rand, of which less than $0.5 \%$ is spent on family planning. You would like to request that this is increased to $1 \%$. Give your reasons for your request and also the reasons why your request will be declined.

7. Climate scientists warn that it is unlikely that we will reach the end of our current century with a habitable planet. Discuss.

The first 5 questions are minor details but the last 2 questions are the greatest challenges we face in the $21^{\text {st }}$ century.

In fact I am going to make the seventh question compulsory for all university students, for all final Bachelor degrees exams for all faculties in every university in the world. The question would have to be passed to graduate.

So question eight is: Would this proposal save the planet?

Chris Ellis is a family physician in Pietermaritzburg, KwaZulu-Natal

E mail: cristobalellis@gmail.com 